\title{
CYP2D6*3 (A2549del), *4 (G1846A), *10 (C100T) and *17 (C1023T) genetic polymorphisms in Iranian breast cancer patients treated with adjuvant tamoxifen
}

\author{
FATEMEH SAGHAFI $^{1}$, EBRAHIM SALEHIFAR ${ }^{2}$, GHASEM JANBABAI $^{3}$, EHSAN ZABOLI $^{3}$, \\ AKBAR HEDAYATIZADEH-OMRAN ${ }^{4}$, OMOLBANIN AMJADI $^{4}$ and SIAVASH MORADI ${ }^{4}$ \\ ${ }^{1}$ Pharmaceutical Research Center, Mazandaran University of Medical Sciences, Sari 48471-16548; \\ ${ }^{2}$ Department of Clinical Pharmacy, Faculty of Pharmacy, Mazandaran University of Medical Sciences, Sari 48471-16548; \\ ${ }^{3}$ Department of Internal Medicine, Faculty of Medicine, Mazandaran University of Medical Sciences, Sari 48471-16548; \\ ${ }^{4}$ Gastrointestinal Cancer Research Center, Mazandaran University of Medical Sciences, Sari 48166-33131, Iran
}

Received June 6, 2018; Accepted September 6, 2018

DOI: $10.3892 /$ br.2018.1145

\begin{abstract}
There is controversy regarding the efficacy of tamoxifen in breast cancer patients who are carriers of cytochrome P450 2D6 (CYP2D6) gene polymorphisms. Poor metabolizer genotypes may not fully convert tamoxifen to its active metabolite endoxifen and thus have less exposure to anti-estrogen therapy. The present study was conducted to identify the prevalence of CYP2D6 genotypes among Iranian breast cancer patients. A total of 84 estrogen receptor-positive breast cancer patients treated at a referral center in the north of Iran were examined. A peripheral blood sample was obtained from each patient to determine the presence of $* 3, * 4, * 10$ and *17 single nucleotide polymorphisms of the CYP2D6 gene by polymerase chain reaction-based restriction fragment-length polymorphism analysis. Of the four genotypes assessed, CYP2D6*4 was the most common variant and was identified in $41(48.8 \%)$ patients as heterozygous $(\mathrm{G} / \mathrm{A})$ and $3(3.6 \%)$ as homozygous (A/A) alleles. CYP2D6*10 heterozygous mutated alleles $(\mathrm{C} / \mathrm{T})$ were also a common genotype that presented in $22(26.2 \%)$ of the study subjects. Variant $* 17$ was less common and was detected only as heterozygous $(\mathrm{C} / \mathrm{T})$ in 3 patients (3.6\%). No CYP2D6*3 heterozygous or homozygous mutated alleles were observed. In conclusion, the frequency of the CYP2D6 nonfunctional alleles $* 4$ and $* 10$ appeared relatively high in Iranian patients with hormone-sensitive breast cancer. This finding may affect the selection of an optimal hormone
\end{abstract}

Correspondence to: Dr Ebrahim Salehifar, Department of Clinical Pharmacy, Faculty of Pharmacy, Mazandaran University of Medical Sciences, Km 18 Khazarabad Road, Khazar Sq., Mazandaran, Sari 48471-16548, Iran

E-mail: esalehifar@mazums.ac.ir

Key words: polymorphism, CYP2D6, HR-positive, tamoxifen, endoxifen therapy, as patients with low CYP2D6 pathway activity may not sufficiently convert tamoxifen to its active metabolite endoxifen.

\section{Introduction}

Cancer is the second leading cause of mortality in the world after cardiovascular diseases and was responsible for 8.7 million mortalities in 2015 (1). Breast cancer is the most common type of malignancy in US women with prevalence rate of $25 \%$ (2). According to the International Agency for Research on Cancer GLOBOCAN estimates, this type of malignancy accounted for 1.7 million cancers and 521,900 mortalities in 2012 worldwide (3).

In Iran, breast cancer is the most common type of cancer in women with an incidence that shows a yearly increase (4-6). An estimated 266,120 new cases of invasive breast cancer are expected to be diagnosed in 2018 in women in the US, along with 63,960 new cases of non-invasive (in situ) breast cancer (7).

Approximately $80 \%$ of breast cancers are estrogen receptor (ER) positive and are therefore eligible for adjuvant endocrine therapy (8). Tamoxifen is the most commonly-used anti-estrogenic drug in adjuvant therapy for hormone-dependent breast cancer, and is able to minimize the risk of recurrence and mortality rate, particularly in pre-menopausal patients (9). Furthermore, the role of this agent as a chemopreventive in high risk women has been made evident (10). Tamoxifen acts through competing with endogenous estrogen for binding to ER and blocks the proliferative actions of estrogen on breast cells (11).

Tamoxifen is considered a 'prodrug', requiring metabolic activation by the cytochrome P450 2D6 (CYP2D6) enzyme. The main metabolites of tamoxifen are endoxifen and 4-hydroxitamoxifen, which have a 30-100 times stronger affinity for binding to ER compared with tamoxifen $(12,13)$. However, $\sim 30 \%$ of patients receiving tamoxifen therapy do not benefit from this therapeutic approach (14). The CYP2D6 gene is highly polymorphic, and metabolism in the CYP2D6 
pathway exhibits marked variation between different racial and ethnic populations (15). The genetic polymorphisms leading to diminished enzymatic activity result in low levels of the main active metabolite endoxifen, which may lead to a poor response to tamoxifen (16).

To date, 105 allelic variants of CYP2D6 have been described (17). These alleles can be classified into three categories, namely functional alleles, reduced-function alleles and nonfunctional alleles, which in turn determine the CYP2D6 phenotypes of poor metabolizers (PMs), intermediate metabolizers (IMs), extensive metabolizers (EMs) and ultra-rapid metabolizers (18).

Four major mutated alleles of CYP2D6 including CYP2D6*3, CYP2D6*4, CYP2D6*10 and CYP2D6*17 are among the most frequent polymorphic alleles in humans $(19,20)$. These alleles have been described as the most frequent mutant alleles throughout different Asian countries (18,21-23). CYP2D6*3 and CYP2D6*4 are associated with PM phenotype, and CYP2D6*10 and CYP2D6*17 are associated with IM phenotype.

It is notable that there are controversies among studies, regarding the association between CYP2D6 genetic polymorphisms and alterations in the efficacy of tamoxifen in patients with breast cancer. To have an improved insight into the polymorphism of CYP2D6 alleles in a cohort of patients with breast cancer, the present study was conducted to determine the CYP2D6 genotyping in a group of patients with breast cancer treated with adjuvant tamoxifen in the north of Iran.

\section{Materials and methods}

Patients. The present study included 84 female patients with hormone-sensitive breast cancer, with or without disease recurrence and taking adjuvant tamoxifen for at least four weeks. The patients who had presented to Tooba Clinic, a university-affiliated clinic in the north of Iran, were prospectively enrolled into the study from June to November 2017. Written informed consent was obtained from each patient prior to enrolment. The study population consisted of all women aged 18 years or higher with a diagnosis of breast cancer. The Internal Review Board of Mazandaran University of Medical Sciences (Sari, Iran) approved the study protocol under the number IR.MAZUMS.REC.1397.90.

Sample collection and DNA extraction. From each patient, $5 \mathrm{ml}$ peripheral blood was drawn and stored in a tube containing EDTA anticoagulant. The samples were stored at $-20^{\circ} \mathrm{C}$. Genomic DNA was extracted from $300 \mu \mathrm{l}$ of the peripheral blood using a column-based DNA isolation kit (Denazist Asia Co., Mashhad, Iran) according to the manufacturer's protocol. The concentration and purity of the extracted DNA was measured using a NanoDrop spectrophotometer (NanoDrop Technologies; Thermo Fisher Scientific, Inc., Waltham, MA, USA).

Immunohistochemical (IHC) analysis. IHC of HER-2/neu protein was performed on paraffin-embedded breast tissue sections, which were fixed in $10 \%$ neutral-buffered formalin at $25^{\circ} \mathrm{C}$ for $24 \mathrm{~h}$. Thereafter, the fixed tissues were deparaffinized in xylene and then rehydrated in a graded ethanol series (100,
96, 80 and 70\%), the samples were cut into 3 to $4-\mu \mathrm{m}$ sections and mounted on Poly-L-Lysine-coated slides. Next, deparaffinization and blocking of endogenous peroxidase activity with $0.3 \%$ hydrogen peroxide in methanol at $25^{\circ} \mathrm{C}$ for $15 \mathrm{~min}$ was performed. This step is important to prevent detachment of tissues from the slides during the antigen retrieval process. Next, antigen retrieval or the high-temperature heating method were used to recover antigenic-sites hidden in tissue samples. Slides were placed in plastic Coplin jars filled with Trizma base solution with $\mathrm{pH}: 9$ and then placed in the center of the microwave oven. The jars were heated for $5 \mathrm{~min}$ in high temperature $900 \mathrm{~W}$. Next, the Coplin jars were removed from the oven to cool for $15 \mathrm{~min}$. At the end, slides were rinse in TBS and distilled water for $20 \mathrm{~min}$.

Treated slides were stained as follows: HER-2/neu immunostaining was performed using rabbit anti-human c-erbB-2 oncoprotein as a primary antibody (cat. no. RMAB008; Dako; Agilent Technologies, Inc., Santa Clara, CA, USA) for $1 \mathrm{~h}$ at $25^{\circ} \mathrm{C}$ (1:100 dilution). Binding of the primary antibody was checked by Dako Quick-Staining, Labelled Streptavidin-Biotin system (Dako; Agilent Technologies, Inc.). Following washing with TBS solution, membranes were incubated with $50 \mu 1$ secondary antibody (cat. no. K5007; Dako; Agilent Technologies, Inc.) at $25^{\circ} \mathrm{C}$ for $30 \mathrm{~min}$. The detection reagent in the kit (cat. no. K5007; Dako; Agilent Technologies, Inc., Santa Clara, CA, USA) consisted of a dextran backbone to which a large number of horseradish peroxidase molecule and secondary antibody molecule had been coupled in order to react to a mouse/ rabbit primary antibody, followed by the addition of diaminobenzidine $(\mathrm{DAB})$ as a chromogen $\left(10 \mathrm{~min}\right.$ at $\left.25^{\circ} \mathrm{C}\right)$. Each slide was scored in a blinded fashion by two pathologists using a light microscope (magnification, x400), according to the manufacturer's protocol. The immunostaining was read in a semiquantitative manner and graded as follows: 0 , $1+, 2+$ and $3+$. In this study we considered $2+$ or higher as HER-2/neu positive (24).

Polymerase chain reaction (PCR). A PCR-based restriction fragment-length polymorphism analysis was performed to determine the CYP2D6 alleles (CYP2D6*3, CYP2D6*4, CYP2D6*10 and CYP2D6*17). PCR was performed using $300 \mathrm{ng}$ of the template DNA, $10 \mu \mathrm{l}$ Taq DNA polymerase $2 \mathrm{x}$ master mix RED (Ampliqon A/S, Odense, Denmark) containing $150 \mathrm{mM}$ Tris- $\mathrm{HCl} \mathrm{pH} 8.5,40 \mathrm{mM}\left(\mathrm{NH}_{4}\right)_{2} \mathrm{SO}_{4}$, $3 \mathrm{mM} \mathrm{MgCl}, 0.2 \%$ Tween-20, $0.4 \mathrm{mM}$ of each dNTP and $0.2 \mathrm{U} / \mu 1$ Ampliqon Taq DNA polymerase, along with $0.015 \mathrm{pM}$ appropriate primers and $3 \mu 1$ nuclease-free water.

The PCR program consisted of an initial denaturation step at $95^{\circ} \mathrm{C}$ for 5 min followed by 35 cycles of denaturation at $95^{\circ} \mathrm{C}$ for $30 \mathrm{sec}$, annealing at $62^{\circ} \mathrm{C}$ for $40 \mathrm{sec}\left(63^{\circ} \mathrm{C}\right.$ for CYP2D6*10), extension at $72^{\circ} \mathrm{C}$ for $30 \mathrm{sec}$, and a final step of extension at $72^{\circ} \mathrm{C}$ for $5 \mathrm{~min}$. Following confirmation of the amplified fragments of the expected size on agarose gel containing DNA green fluorescent dye (Pars Tous Biotechnology, Mashhad, Iran), the PCR products were restriction-digested with $10 \mathrm{U} / \mu 1$ $M s p \mathrm{I}, B s t \mathrm{NI}$ and $H p h \mathrm{I}$ (Fermentas; Thermo Fisher Scientific, Inc., Waltham, MA, USA) at $37^{\circ} \mathrm{C}\left(55^{\circ} \mathrm{C}\right.$ for CYP2D6*10) for $16 \mathrm{~h}$. The DNA fragments were electrophoresed through a $3 \%$ agarose gel containing DNA green fluorescent dye for 
Table I. CYP2D6 variant primers, product lengths and enzymes used for polymerase chain reaction-restriction fragment length polymorphism analysis.

\begin{tabular}{|c|c|c|c|c|c|}
\hline Variant & rs no. & Primers, 5'-3' & Product length, bp & Enzyme & Refs. \\
\hline CYP2D6*3 & rs35742686 & $\begin{array}{l}\text { F-ATGAGCTGCTAACTGAGCCC } \\
\text { R-CCGAGAGCATACTCGGGAC }\end{array}$ & 270 & MspI & (43) \\
\hline CYP2D6*4 & rs3892097 & $\begin{array}{l}\text { F-TGCCGCCTTCGCCAACCACT } \\
\text { R-TCGCCCTGCAGAGACTCCTC }\end{array}$ & 309 & $B s t \mathrm{NI}$ & (26) \\
\hline CYP2D6*10 & Rs1065852 & $\begin{array}{l}\text { F-GTGCTGAGAGTGTCCTGCC } \\
\text { R-CACCCACCATCCATGTTTGC }\end{array}$ & 344 & $H p h \mathrm{I}$ & (26) \\
\hline CYP2D6*17 & rs28371706 & $\begin{array}{l}\text { F-CGGTGGTCGTGCCTCAATG } \\
\text { R-CCCGGGTCCCACGGAAATCT }\end{array}$ & 167 & $H p h \mathrm{I}$ & (44) \\
\hline
\end{tabular}

CYP2D6, cytochrome P450 2D6; rs, reference single nucleotide polymorphism; F, forward; R, reverse.

Table II. The length of products and products of digestion were shown.

\begin{tabular}{|c|c|c|c|c|}
\hline Polymorphisms & Product length (bp) & Enzyme & Products of digestion length & Refs \\
\hline CYP2D6*3 & 270 & MspI & $\begin{array}{c}\text { Wild-type (AA): } 188 / 82 \\
\text { Heterozygote (A/-): 188/168/20 } \\
\text { Mutant (-/-): 168/20 }\end{array}$ & $(43)$ \\
\hline CYP2D6*4 & 309 & $B s t \mathrm{NI}$ & $\begin{array}{c}\text { Wild-type (GG): 201/108 } \\
\text { Heterozygote (GA): 309/201/108 } \\
\text { Mutant (AA): } 309\end{array}$ & (26) \\
\hline CYP2D6*10 & 344 & $H p h \mathrm{I}$ & $\begin{array}{l}\text { Wild-type (CC): 282/62 } \\
\text { Heterozygote (CT): 282/182/100/62 } \\
\text { Mutant (TT): } 182 / 100 / 62\end{array}$ & (26) \\
\hline CYP2D6*17 & 167 & $H p h \mathrm{I}$ & $\begin{array}{c}\text { Wild-type (TT): } 167 \\
\text { Heterozygote (CT): 167/88/55 } \\
\text { Mutant (CC): } 88 / 55\end{array}$ & (44) \\
\hline
\end{tabular}

CYP2D6*3, *10 and *17 and through a $2 \%$ agarose gel for CYP2D6*4 as in other studies $(25,26)$. Table I presents a summary of the single nucleotide polymorphisms, primers, product lengths and restriction enzymes. The expected digested fragments are shown in Table II.

Statistical analysis. Considering the non-interventional characteristics of the study, only descriptive statistics (e.g., mean, standard deviation, frequency and percent) were computed and reported using SPSS 25.0 (IBM Corp., Armonk, NY, USA).

\section{Results}

Baseline characteristics. Baseline characteristics of the patients (Table III) and also clinical and pathological features of the patients (Table IV) were presented. The mean age was $45.4 \pm 6.8$ years (range, 29-63 years). Almost half of patients had a positive family history of breast cancer. Most of patients were in the premenopausal state $(89.3 \%)$. HER-2 negative state was found in $\sim 55 \%$ of the patients. Majority of patients $(\sim 93 \%)$ were hormone-positive. Regarding staging, most patients
(54.8\%) were assigned as Stage 2 disease. More than $80 \%$ of patient did not have any evidence of metastasis. Most patients (about $85 \%$ ) were undergone adjuvant chemoradiation.

Genotypes of patients. The allele and genotype frequency distributions of the CYP2D6*3 (A2549del), *4 (G1846A), $* 10(\mathrm{C} 100 \mathrm{~T})$ and $* 17(\mathrm{C} 1023 \mathrm{~T})$ variants were analyzed in the blood samples of 84 patients with ER-positive breast cancer.

The figures present the alleles in the pattern of the fragments digested for the detection of CYP2D6*3 (Fig. 1), CYP2D6*4 (Fig. 2), CYP2D6*10 (Fig. 3) and CYP2D6*17 (Fig. 4).

No mutant CYP2D6*3 heterozygous (A/-) or homozygous (-/-) alleles were observed in the study population; however, mutant CYP2D6*10 heterozygous alleles $(C / T)$ were present in 22 cases (26.2\%). Regarding the metabolizing phenotype, CYP2D6 activity was classified as poor, intermediate or extensive, as presented in Table V. Of the four genotype groups, 3 (3.6\%) and $41(48.8 \%)$ of the patients were PMs (CYP2D6*4 homozygote, 
Table III. Baseline characteristics of patients.

\begin{tabular}{lcc}
\hline Variable & $\mathrm{n}$ & $\%$ \\
\hline Number of patients & 84 & 100.0 \\
Mean age, years (standard deviation) & $45.4(6.8)$ & \\
Family history & & \\
$\quad$ Negative & 43 & 51.2 \\
Positive & 41 & 48.8 \\
Marital status & & \\
Married & 73 & 86.9 \\
$\quad$ Unmarried & 11 & 13.1 \\
Menopausal status & & \\
Premenopausal & 75 & 89.3 \\
Post-menopausal & 9 & 10.7 \\
\hline
\end{tabular}

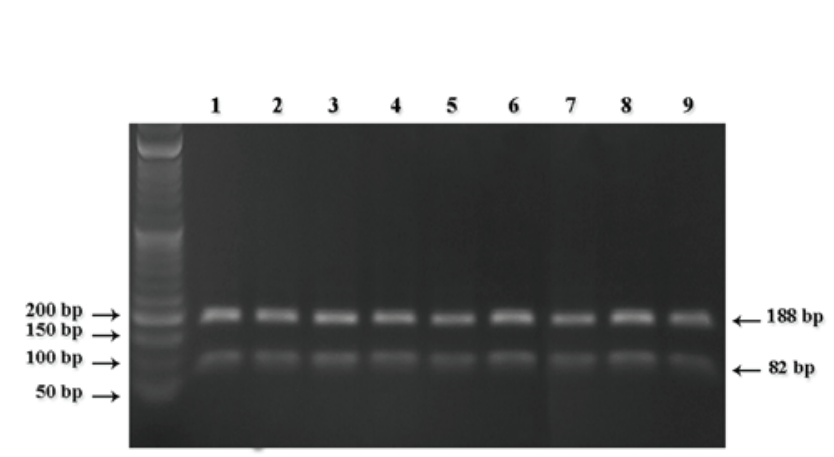

Figure 1. Pattern of $3 \%$ agarose gel electrophoresis of cytochrome $\mathrm{P} 450$ $2 \mathrm{D} 6 * 3$ digested segments. All lanes show homozygous samples for the wild-type (AA).

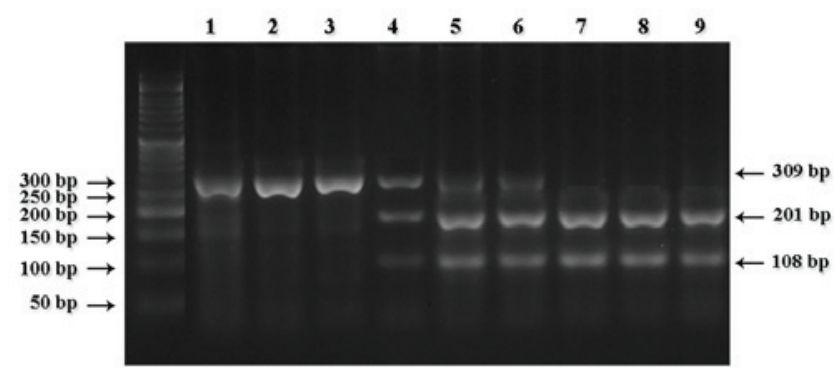

Figure 2. Pattern of $2 \%$ agarose gel electrophoresis of cytochrome P450 2D6*4 digested segments. Lanes 1-3 show homozygous samples for the mutant type (AA); lanes 7-9 wild-type samples (GG); and lanes 4-6 heterozygous samples (GA), respectively.

A/A) and IMs (CYP2D6*4 heterozygote, G/A), respectively. Variant $* 17$ was less common and was detected only as heterozygous $(\mathrm{C} / \mathrm{T})$ in 3 patients $(3.6 \%)$, classified as IMs.

\section{Discussion}

Genetic polymorphism of CYP2D6 in Iranian breast cancer patients treated with tamoxifen was the focus of the present study. There has been numerous studies performed on this topic with conflicting results, particularly when examining the clinical impact of this variation on patient outcome and response
Table IV. Clinical characteristics and pathological features of patients.

\begin{tabular}{lrc}
\hline Variable & $\mathrm{n}$ & $\%$ \\
\hline HER-2/neu & & \\
0 & 38 & 45.2 \\
$1+$ & 20 & 23.8 \\
$2+$ & 9 & 10.7 \\
$3+$ & 17 & 20.2
\end{tabular}

Estrogen/progesterone receptor status

Positive/positive $(+/+)$

Positive/negative (+/-)

78

6

92.9

Recurrence

Positive

Negative

TNM stage

I

10

11.9

II

46

54.8

III

16.7

IV

Lymph node involvement

Positive

78.6

Negative

66

21.4

Metastasis

Negative

Bone

Liver

Bone and liver

History of resection

Positive

Negative

Type of resection

Radical mastectomy $\quad 1 \quad 1.2$

Modified radical mastectomy $\quad 49 \quad 59.8$

Conservative

39.0

Previous chemotherapy

Positive

95.2

Negative

Type of chemotherapy

Adjuvant

Neo-adjuvant

Concurrent diseases

Positive

44.1

Negative

History of radiotherapy

Positive

Negative

History of oral contraceptive pill use

$\begin{array}{lll}\text { Positive } & 44 & 52.4 \\ \text { Negative } & 40 & 47.6\end{array}$

HER-2/neu expression status was based on results of immunohistochemistry: 0 or $1+$ (negative), $2+$ (borderline) or $3+$ (positive). TNM staging was according to the American Joint Committee on Cancer staging manual (7th edition) (45). 
Table V. CYP2D6 genotype and metabolizer category.

\begin{tabular}{llll}
\hline Frequency, $\%(\mathrm{n})$ & Genotype & Activity & Category \\
\hline PM & None & Two null alleles (CYP2D6 *4) & $* 4(\mathrm{AA}): 3.6(3)$ \\
IM & Reduced & One null allele (CYP2D6 *4, *10, *17) & $* 4(\mathrm{GA}): 48.8(41)$ \\
& & $* 10(\mathrm{CT}): 26.2(22)$ \\
& & & $* 17(\mathrm{CT}): 3.6(3)$ \\
EM & Normal & Two wild-type/normal alleles & $* 3(\mathrm{AA}): 100.0(84)$ \\
& & (CYP2D6 $3, * 4, * 10, * 17)$ & $* 4(\mathrm{GG}): 47.6(40)$ \\
& & & $* 10(\mathrm{CC}): 73.8(62)$ \\
& & & $* 17(\mathrm{CC}): 96.4(81)$
\end{tabular}

CYP2D6, cytochrome P450 2D6; PM, poor metabolizer; IM, intermediate metabolizer; EM, extensive metabolizer.

Table VI. Frequency of four CYP2D6 non-functional alleles in different populations.

\begin{tabular}{|c|c|c|c|c|c|c|c|c|}
\hline \multirow[b]{2}{*}{ Population } & \multirow[b]{2}{*}{ Year } & \multirow[b]{2}{*}{$\mathrm{N}$} & \multirow[b]{2}{*}{ Patient Status } & \multicolumn{4}{|c|}{ Allele frequency $(\%)$} & \multirow[b]{2}{*}{ Refs. } \\
\hline & & & & $* 3$ & $* 4$ & $* 10$ & $* 17$ & \\
\hline Iranian & 2018 & 84 & $\mathrm{BCP}$ & $\mathrm{Nd}$ & 52.4 & 26.2 & 3.6 & Present study \\
\hline Iranian & 2009 & 100 & $\mathrm{HP}$ & - & 12.5 & 9.0 & $\mathrm{Nd}$ & (26) \\
\hline Iranian & 2011 & 100 & $\mathrm{HP}$ & 0.5 & 9.0 & - & - & $(46)$ \\
\hline Iranian & 2015 & 101 & $\mathrm{BCP}$ & - & 36.6 & - & - & $(37)$ \\
\hline Japanese & 2000 & 412 & $\mathrm{HP}$ & - & 0.2 & 38.1 & - & $(22)$ \\
\hline Chinese & 2009 & 100 & $\mathrm{HP}$ & - & 1.0 & 49.0 & - & $(21)$ \\
\hline Spanish & 2006 & 105 & $\mathrm{HP}$ & 0.95 & 13.8 & - & - & (39) \\
\hline Brazilian & 2016 & 80 & $\mathrm{BCP}$ & - & 13.75 & 21.25 & 10.0 & $(40)$ \\
\hline Pakistani & 2016 & 232 & $\mathrm{BCP}$ & - & - & 7.0 & - & $(35)$ \\
\hline South-Indian & 2006 & 447 & $\mathrm{HP}$ & $\mathrm{Nd}$ & 7.3 & 10.2 & $\mathrm{Nd}$ & $(36)$ \\
\hline Malaysian Indian & 2016 & 80 & $\mathrm{BCP}$ & - & 28.6 & 21.4 & - & $(18)$ \\
\hline Malaysian Malay & 2016 & 80 & $\mathrm{BCP}$ & - & 2.9 & 54.8 & - & $(18)$ \\
\hline Malaysian Chinese & 2016 & 80 & $\mathrm{BCP}$ & - & $\mathrm{Nd}$ & 71.4 & - & (18) \\
\hline Malaysian Malay & 2001 & 107 & $\mathrm{HP}$ & - & 2.8 & 49.5 & 0.5 & $(42)$ \\
\hline Korean & 2006 & 400 & HP & - & - & 45.0 & - & $(34)$ \\
\hline Thai & 2012 & 67 & $\mathrm{BCP}$ & - & - & 51.0 & & $(23)$ \\
\hline Turkish & 2009 & 100 & $\mathrm{HP}$ & - & 28.0 & - & - & $(38)$ \\
\hline Turkish & 2005 & 140 & $\mathrm{HP}$ & 2.5 & 13.9 & - & - & $(47)$ \\
\hline Saudi Arabians & 1997 & 101 & $\mathrm{HP}$ & - & 3.5 & 3.0 & 3.0 & (20) \\
\hline USA & 2006 & 158 & BCP & 0.013 & 0.161 & 0.035 & - & (41) \\
\hline
\end{tabular}

Nd, not detected; HP, healthy population; BCP, breast cancer population.

to hormonal therapy $(23,27,28)$. Of the four CYP2D6 alleles evaluated in the present study, the most common alleles were CYP2D6*4 and CYP2D6*10, followed by CYP2D6*17. The CYP2D6*10 allele has been described as the most frequently mutated gene in various Asian countries, including China, Japan and Korea (29-31); however, the CYP2D6*4 allele is reportedly the most common among Caucasian populations $(32,33)$. Table VI presents the frequencies of the CYP2D6 nonfunctional alleles $* 3, * 4, * 10$ and $* 17$ in different populations.

Genotype combinations were used to categorize CYP2D6 metabolism phenotypes as PM, IM and EM. The three major mutated alleles of CYP2D6 (*3, *4 and *5) account for the majority of PM alleles (19). Asians have exhibited a high prevalence for the IM allele CYP2D6*10, which may lead to a reduced activity of the enzyme and lower serum concentrations of endoxifen (31). This finding may explain the poor survival outcome in Asian women with breast cancer receiving adjuvant tamoxifen therapy (32).

The allele frequency of CYP2D6*10 was $26.2 \%$ in the present study, which is markedly less than that observed in Korea [45.0\% (34)] and other eastern countries, including Thailand (51.0\%) (18), Malaysia (54.8\% in Malays and $71.4 \%$ 


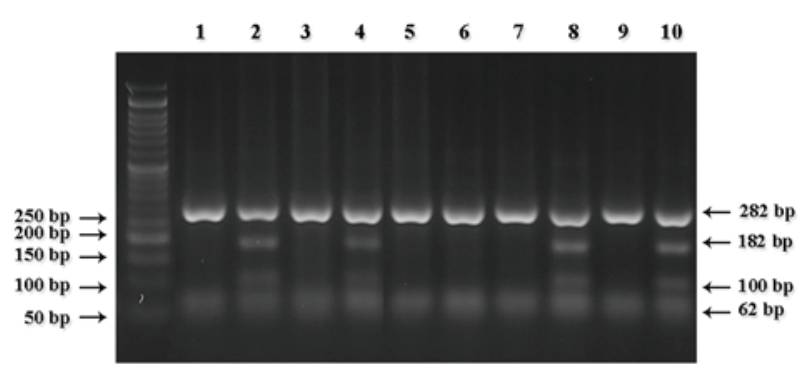

Figure 3. Pattern of $2.5 \%$ agarose gel electrophoresis of cytochrome $\mathrm{P} 450$ 2D6*10 digested segments. Lanes 2, 4, 8 and 10 show heterozygous samples (CT); all other lanes show wild-type samples (CC).

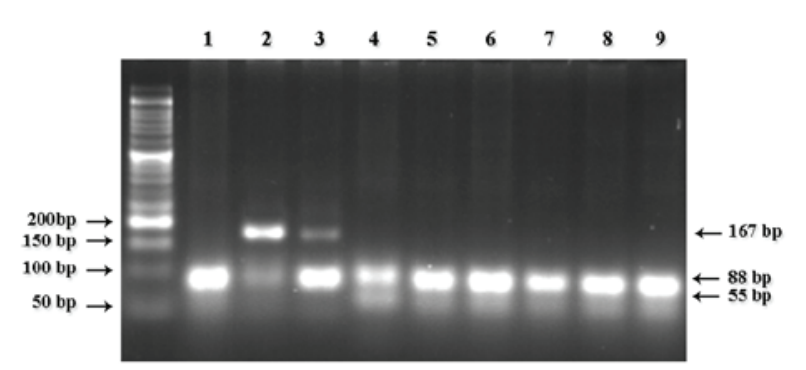

Figure 4. Pattern of 3\% agarose gel electrophoresis of cytochrome P450 2D6*17 digested segments. Lanes 2 and 3 show heterozygous samples (CT) and lanes 1 and 4-9 show wild-type homozygous samples.

in Malaysian-Chinese) (23) and China (49.0\%) (21), but higher than in Pakistan (7.0\%) (35) and South India (10.2\%) (36). Previous study reported the prevalence of CYP2D6*10 as $\sim 9.0 \%$ in Iranian Azerbaijanis (26), but another study of Iranians of different ethnicities reported the prevalence of the allele to be $39.3 \%$ (24.3\% for homozygous $\mathrm{T} / \mathrm{T}$ and $15.0 \%$ for heterozygous $\mathrm{C} / \mathrm{T})(25)$.

The frequency of CYP2D $6 * 4$ varies across different races, and frequencies of 36.6, 28.6, 28.0, 13.8, 13.8, 7.3 and $0.2 \%$ have been reported in Iranians, Malaysian Indians, Turks, Spanish subjects, Brazilians, South-Indians and North Americans, respectively $(18,36-41)$. Conversely, the frequency of CYP2D6*4 varies from 0.2 to $3.5 \%$ among Japanese, Chinese and Saudi Arabians, which is considered relatively low (20-22). In the present study, a notably higher prevalence of $52.4 \%$ was observed for the CYP2D6*4 allele.

According to the present findings, the low frequency or absence of the CYP2D6*3 and *17 alleles in the Iranian population appears to reflect a general similarity $(20,36,39,42)$.

However, a major limitation of the present study was the relatively small number of patients. Although the results may provide clinical indication and rational for the administration of tamoxifen as first-line hormone therapy, the findings require confirmation in a larger group of patients with breast cancer. Furthermore, the effect of the genetic polymorphisms in terms of treatment efficacy of adjuvant tamoxifen warrants further studies.

To conclude, the present study demonstrated that the CYP2D6 nonfunctional alleles $* 4$ and $* 10$ were relatively frequent in an Iranian population of breast cancer patients. This finding may affect the selection of an optimal hormone therapy, as patients with low CYP2D6 pathway activity may not sufficiently convert tamoxifen to its active metabolite endoxifen.

\section{Acknowledgements}

This article is derived from the thesis 'Evaluation of CYP2D6*3, *4, *10 and $* 17$ polymorphisms on the Tamoxifen Pharmacokinetics in Breast Cancer Patients, Mazandaran, Iran' supervised by Professor Ebrahim Salehifar and submitted by Dr Fatemeh Saghafi to the Faculty of Pharmacy of Mazandaran University of Medical Sciences, Sari, Iran, in partial fulfillment of the Requirements for the Degree of Doctor of Philosophy (Ph.D.) in Clinical Pharmacy.

\section{Funding}

The manuscript was financially supported by a grant from the Research and Technology Department of Mazandaran University of Medical Sciences (grant no. 1397.90), Sari, Iran. Data sharing is not applicable to this article, as no datasets were generated or analyzed during the current study.

\section{Availability of data and materials}

All data generated or analysed during this study are included in this published article.

\section{Authors' contributions}

FS was involved in collecting data and performing the genotyping. ES designed the study and supervised all aspects of the study. GJ and EZ aided in the recruitment of the patients and in the collection of clinical data. AHO and OA performed the DNA extraction and RFLP PCR experiments. SM was involved in the design of the study and data analysis. All authors have read the manuscript and its revisions and confirmed the contents of the manuscript.

\section{Ethics approval and consent to participate}

All patients signed an informed consent form prior to participation in the study. The study was approved by the Ethics Committee of Mazandaran University of Medical Sciences, Sari, Iran (approval no. IR.MAZUMS.REC.1397.90).

\section{Patient consent for publication}

Consent for publication was agreed upon in the written consent forms signed by the patients.

\section{Competing interests}

The authors declare that they have no competing interests regarding the publication of this paper.

\section{References}

1. Fitzmaurice C, Allen C, Barber RM, Barregard L, Bhutta ZA, Brenner $\mathrm{H}$, et al: Global, regional, and national cancer incidence, mortality, years of life lost, years lived with disability, and disability-adjusted life-years for 32 cancer groups, 1990 to 2015: A systematic analysis for the global burden of disease study. JAMA Oncol 3: 524-548, 2017.

2. Siegel RL, Miller KD and Jemal A: Cancer statistics, 2015. CA Cancer J Clin 65: 5-29, 2015. 
3. Torre LA, Bray F, Siegel RL, Ferlay J, Lortet-Tieulent J and Jemal A: Global cancer statistics, 2012. CA Cancer J Clin 65: 87-108, 2015

4. Kolahdoozan S, Sadjadi A, Radmard AR and Khademi H: Five common cancers in Iran. Arch Iran Med 13: 143-146, 2010.

5. Mousavi SM, Montazeri A, Mohagheghi MA, Jarrahi AM, Harirchi I, Najafi M and Ebrahimi M: Breast cancer in Iran: An epidemiological review. Breast J 13: 383-391, 2007.

6. Karimi A, Shandiz FH, Sharifzadeh GR, Zoubin F, Fatemeh T and Rahmani S: Breast cancer in Iran. Life Sci J 10: 2013.

7. Kumar G: Symptom Clusters and Quality of Life Trajectories in Breast Cancer Patients Before and After Chemotherapy. University of Nebraska Medical Center, 2018.

8. Motaghed M: Cytotoxic, cytostatic and anti-estrogenic effect of Thymoquinone on estrogen receptor-positive breast cancer MCF7 cell line. American Journal of Life Sciences 3: 7-14, 2015.

9. Hoskins JM, Carey LA and McLeod HL: CYP2D6 and tamoxifen: DNA matters in breast cancer. Nat Rev Cancer 9: 576-586, 2009.

10. Taylor R and Taguchi K: Tamoxifen for breast cancer chemoprevention: Low uptake by high-risk women after evaluation of a breast lump. Ann Fam Med 3: 242-247, 2005.

11. Kumar KS and Kumar MM: Antiestrogen therapy for Breast Cancer: An overview. Cancer Ther 6: 2008

12. Kiyotani K, Mushiroda T, Sasa M, Bando Y, Sumitomo I, Hosono N, Kubo M, Nakamura Y and Zembutsu H: Impact of CYP2D6*10 on recurrence-free survival in breast cancer patients receiving adjuvant tamoxifen therapy. Cancer Sci 99: 995-999, 2008.

13. Morrow PK, Serna R, Broglio K, Pusztai L, Nikoloff DM Hillman GR, Fontecha M, Li R, Michaud L, Hortobagyi G, et al: Effect of CYP2D6 polymorphisms on breast cancer recurrence. Cancer 118: 1221-1227, 2012 .

14. Group EBCTC: Tamoxifen for early breast cancer: An overview of the randomised trials. Early Breast Cancer Trialists Collaborative Group. Lancet 351: 1451-1467, 1998.

15. Bertilsson L, Dahl ML, Dalén P and Al-Shurbaji A: Molecular genetics of CYP2D6: Clinical relevance with focus on psychotropic drugs. Br J Clin Pharmacol 53: 111-122, 2002

16. van Schaik RH: Cancer treatment and pharmacogenetics of cytochrome P450 enzymes. Invest New Drugs 23: 513-522, 2005.

17. Dai DP, Geng PW, Wang SH, Cai J, Hu LM, Nie JJ, Hu JH, Hu GX and Cai JP: In vitro functional assessment of 22 newly identified CYP2D6 allelic variants in the Chinese population. Basic Clin Pharmacol Toxicol 117: 39-43, 2015.

18. Chin FW, Chan SC, Abdul Rahman S, Noor Akmal S and Rosli R: CYP2D6 genetic polymorphisms and phenotypes in different ethnicities of Malaysian breast cancer patients. Breast J 22: 54-62, 2016.

19. Yagihashi T, Mizuno M, Chino B, Sato Y, Sakuma K, Takebayashi T, Takao T and Kosaki K: Effects of the CYP2D6*10 alleles and co-medication with CYP2D6-dependent drugs on risperidone metabolism in patients with schizophrenia. Hum Psychopharmacol 24: 301-308, 2009.

20. McLellan RA, Oscarson M, Seidegård J, Evans DA and Ingelman-Sundberg M: Frequent occurrence of CYP2D6 gene duplication in Saudi Arabians. Pharmacogenetics 7: 187-191, 1997.

21. Zhou Q, Yu XM, Lin HB, Wang L, Yun QZ, Hu SN and Wang DM: Genetic polymorphism, linkage disequilibrium, haplotype structure and novel allele analysis of CYP2C19 and CYP2D6 in Han Chinese. Pharmacogenomics J 9: 380-394, 2009.

22. Nishida Y, Fukuda T, Yamamoto I and Azuma J: CYP2D6 genotypes in a Japanese population: Low frequencies of CYP2D6 gene duplication but high frequency of CYP2D6*10. Pharmacogenetics 10: 567-570, 2000.

23. Rungwanonchai P, Ayudhya DPN, Areepium N, Voravud N and Satthaporn S: Prevalence of CYP2D6* 10 Genotype in Thai Breast Cancer Patients. Wētchasān phǣt Thahān Bok 65: 113-118, 2012.

24. Roepman P, Horlings HM, Krijgsman O, Kok M, Bueno-de-Mesquita JM, Bender R, Linn SC, Glas AM, van de Vijver MJ, et al: Microarray-based determination of estrogen receptor, progesterone receptor, and HER2 receptor status in breast cancer. Clin Cancer Res 15: 7003-7011, 2009.

25. Bagheri A, Kamalidehghan B, Haghshenas M, Azadfar P, Akbari L, Sangtarash MH, Vejdandoust F, Ahmadipour F, Meng GY and Houshmand M: Prevalence of the CYP2D6*10 $(\mathrm{C} 100 \mathrm{~T}), * 4(\mathrm{G} 1846 \mathrm{~A})$, and $* 14(\mathrm{G} 1758 \mathrm{~A})$ alleles among Iranians of different ethnicities. Drug Des Devel Ther 9: 2627-2634, 2015.

26. Kouhi H, Hamzeiy H, Barar J, Asadi M and Omidi Y: Frequency of five important CYP2D6 alleles within an Iranian population (Eastern Azerbaijan). Genet Test Mol Biomarkers 13: 665-670, 2009.
27. Zhou LP, Luan H, Dong XH, Jin GJ, Man DL and Shang H: Genetic variants of CYP2D6 gene and cancer risk: A HuGE systematic review and meta-analysis. Asian Pac J Cancer Prev 13: 3165-3172, 2012

28. Gutman G, Morad T, Peleg B, Peretz C, Bar-Am A, Safra T and Grisaru D: CYP1A1 and CYP2D6 gene polymorphisms in Israeli Jewish women with cervical cancer. Int J Gynecol Cancer 19 1300-1302, 2009

29. Teh LK and Bertilsson L: Pharmacogenomics of CYP2D6: Molecular genetics, interethnic differences and clinical importance. Drug Metab Pharmacokinet 27: 55-67, 2012.

30. Oscarson M: Pharmacogenetics of drug metabolising enzymes: Importance for personalised medicine. Clin Chem Lab Med 41: 573-580, 2003

31. Ramamoorthy Y, Tyndale RF and Sellers EM: Cytochrome P450 2D6.1 and cytochrome P450 2D6.10 differ in catalytic activity for multiple substrates. Pharmacogenetics 11: 477-487, 2001.

32. Xu Y, Sun Y, Yao L, Shi L, Wu Y, Ouyang T, Li J, Wang T, Fan Z, Fan T, et al: Association between CYP2D6 *10 genotype and survival of breast cancer patients receiving tamoxifen treatment. Ann Oncol 19: 1423-1429, 2008.

33. LLerena A Naranjo MEG, Rodrigues-Soares F, Penas-LLedó EM, Fariñas H and Tarazona-Santos E: Interethnic variability of CYP2D6 alleles and of predicted and measured metabolic phenotypes across world populations. Expert Opin Drug Metab Toxicol 10: 1569-1583, 2014

34. Lee SY, Sohn KM, Ryu JY, Yoon YR, Shin JG and Kim JW: Sequence-based CYP2D6 genotyping in the Korean population. Ther Drug Monit 28: 382-387, 2006.

35. Nazir N, Waheed A, Farhat K, Ismail M and Mansoor Q: Frequency of CYP2D6*10 genotypes in Pakistani breast cancer patients taking adjuvant tamoxifen. J Pak Med Assoc 66: $1554-1558,2016$

36. Naveen AT, Adithan C, Soya SS, Gerard N and Krishnamoorthy R: CYP2D6 genetic polymorphism in South Indian populations. Biol Pharm Bull 29: 1655-1658, 2006.

37. Yazdi MF, Rafieian S, Gholi-Nataj M, Sheikhha MH, Nazari T and Neamatzadeh H: CYP2D6 Genotype and risk of recurrence in tamoxifen treated breast cancer patients. Asian Pac J Cancer Prev 16: 6783-6787, 2015

38. Erden G, Acar FS, Inal EE, Soydas AO, Ozoran K, Bodur H and Yildirimkaya MM: Frequency of mutated allele CYP2D6*4 in the Turkish ankylosing spondylitis patients and healthy controls. Rheumatol Int 29: 1431-1434, 2009.

39. Menoyo A, del Rio E and Baiget M: Characterization of variant alleles of cytochrome CYP2D6 in a Spanish population. Cell Biochem Funct 24: 381-385, 2006.

40. De Ameida Melo M, De Vasconcelos-Valença RJ, Neto FM, Borges RS, Costa-Silva DR, Da Conceição Barros-Oliveira M, Borges US, Alencar AP, Silva VC and Da Silva BB: CYP2D6 gene polymorphisms in Brazilian patients with breast cancer treated with adjuvant tamoxifen and its association with disease recurrence. Biomed Rep 5: 574-578, 2016

41. Borges S, Desta Z, Li L, Skaar TC, Ward BA, Nguyen A, Jin Y, Storniolo AM, Nikoloff DM and Wu L: Quantitative effect of CYP2D6 genotype and inhibitors on tamoxifen metabolism: Implication for optimization of breast cancer treatment. Clin Pharmacol Ther 80: 61-74, 2006.

42. Teh LK, Ismail R, Yusoff R, Hussein A, Isa MN and Rahman AR: Heterogeneity of the CYP2D6 gene among Malays in Malaysia. J Clin Pharm Ther 26: 205-211,2001.

43. Topić E, Stefanović M, Nikolić V, Zoricić I, Ivanisević AM and Žuntar I: Detection of CYP2D6*3 and 2D6*4 allelic variants by PCR-restriction fragment length polymorphism. Clin Chem Lab Med 36: 655-658, 1998

44. Varela N, Quiñones LA, Stojanova J, Garay J, Cáceres D, Cespedes S, Sasso J and Miranda C: Characterization of the CYP2D6 drug metabolizing phenotypes of the Chilean mestizo population through polymorphism analyses. Pharmacol Res 101: 124-129, 2015.

45. Edge SB and Compton CC: The American Joint Committee on Cancer: the 7th edition of the AJCC cancer staging manual and the future of TNM. Ann Surg Oncol 17: 1471-1474, 2010.

46. Hashemi-Soteh SM, Sarzare F, Merat F, Salehifar E and Shiran MR: Frequencies of three CYP2D6 nonfunctional alleles (CYP2D6*3, $* 4$, and $* 6$ ) within an Iranian population (Mazandaran). Genet Test Mol Biomarkers 15: 821-825, 2011.

47. Aydin M, Hatirnaz O, Erensoy N and Ozbek U: CYP2D6 and CYP1A1 mutations in the Turkish population. Cell Biochem Funct 23: 133-135, 2005. 